\title{
Aligning integrated assessment modelling with socio-technical transition insights: An application to low-carbon energy scenario analysis in Europe
}

\author{
Mariësse A.E. van Sluisveld ${ }^{\mathrm{a}, \mathrm{b}, *}$, Andries F. Hof ${ }^{\mathrm{a}, \mathrm{b}}$, Samuel Carrara ${ }^{\mathrm{c}, \mathrm{d}, \mathrm{e}}$, Frank W. Geels ${ }^{\mathrm{f}}$, \\ Måns Nilsson ${ }^{g}$, Karoline Rogge ${ }^{\mathrm{h}, \mathrm{j}}$, Bruno Turnheim ${ }^{\mathrm{f}, \mathrm{j}, \mathrm{j}, \mathrm{k}}$, Detlef P. van Vuuren ${ }^{\mathrm{a}, \mathrm{b}}$ \\ ${ }^{\text {a }}$ Copernicus Institute of Sustainable Development, Utrecht University, Utrecht, The Netherlands \\ ${ }^{\mathrm{b}}$ PBL Netherlands Environmental Assessment Agency, The Hague, The Netherlands \\ ${ }^{\mathrm{c}}$ Fondazione Eni Enrico Mattei (FEEM), Milan, Italy \\ ${ }^{\mathrm{d}}$ Centro Euro-Mediterraneo sui Cambiamenti Climatici (CMCC), Milan, Italy \\ ${ }^{\mathrm{e}}$ Renewable and Appropriate Energy Laboratory (RAEL) and Energy and Resources Group (ERG), University of California, Berkeley, United States \\ ${ }^{\mathrm{f}}$ Alliance Manchester Business School, University of Manchester, Manchester, UK \\ ${ }^{\mathrm{g}}$ Stockholm Environment Institute (SEI), Stockholm, Sweden \\ ${ }^{\mathbf{h}}$ Fraunhofer Institute for System and Innovation Research (Fraunhofer ISI), Karlsruhe, Germany \\ ${ }^{\mathrm{i}}$ Laboratoire Interdisciplinaire Sciences Innovations Sociétés (UMR-LISIS) (CNRS-IFRIS), University Paris-Est Marne-la-Vallée, Paris, France \\ ${ }^{\mathrm{j}}$ Science Policy Research Unit (SPRU), University of Sussex, Brighton, UK \\ ${ }^{\mathbf{k}}$ Department of Geography, King's College London, UK
}

\section{A R T I C L E I N F O}

\section{Keywords:}

Interdisciplinary

MLP

Integrated assessment

IAM

Socio-technical transitions

\begin{abstract}
A B S T R A C T
In this study, we present and apply an interdisciplinary approach that systematically draws qualitative insights from socio-technical transition studies to develop new quantitative scenarios for integrated assessment modelling. We identify the transition narrative as an analytical bridge between socio-technical transition studies and integrated assessment modelling. Conceptual interaction is realised through the development of two contrasting transition narratives on the role of actors in meeting the European Unions' $80 \%$ greenhouse gas emission reduction objective for 2050. The first transition narrative outlines how large-scale innovation trajectories are driven by incumbent actors, whereas the second transition narrative assumes more 'alternative' strategies by new entrants with strong opposition to large-scale technologies. We use the multi-level perspective to draw out plausible storylines on actor positioning and momentum of change for several technological and social nicheinnovations in both transition narratives. These storylines are then translated into quantitative scenarios for integrated assessment modelling. Although both developed transition pathways align with the European Union's low-carbon objective for 2050, we find that each pathway depicts a substantial departure from systems that are known to date. Future research could focus on further systematic (joint) development of operational links between the two analytical approaches, as well as work on improved representation of demand-oriented solutions in techno-economic modelling.
\end{abstract}

\section{Introduction}

Transitions towards a low-carbon society depend on the progression of a wide variety of different factors and processes. Integrated Assessment Models (IAMs) are computer-based instruments that are commonly used to analytically support our understanding of long-term transitions, global climate change and the various complex interlinkages between human and natural subsystems. As IAMs have a comprehensive representation of the global system, they are commonly used to evaluate the implications of different policy decisions on both the human and natural system over time. However, the main drawback is that these instruments can only focus on those elements that can be captured in mathematical formulations. Moreover, as IAMs apply (energy) engineering principles and neo-classical economics, they generally frame system transitions in terms of cost-effectiveness and technological change alone.

This techno-economic focus has led to a discussion among scholars on the interpretation of IAM scenario results (see e.g. Anderson and Peters, 2016; Fuss et al., 2014; Kruger et al., 2016), especially as scenarios may present outcomes that could be controversial in the light of other criteria such as risk and societal support. For instance, researchers have pointed at the large-scale deployment of bioenergy and $\mathrm{CO}_{2}$

\footnotetext{
* Corresponding author at: PBL Netherlands Environmental Assessment Agency, The Hague, The Netherlands.

E-mail addresses: mariesse.vansluisveld@gmail.com, mariesse.vansluisveld@pbl.nl (M.A.E. van Sluisveld).
} 
capture and storage systems (creating so-called 'negative emissions', a geoengineering strategy to reverse damaging impacts from rising GHG emission levels) in most of the low-carbon transition depictions in the 5th Assessment Report (AR5) by the United Nations' Intergovernmental Panel on Climate Change (IPCC) (Clarke et al., 2014). These low-carbon transition scenarios thus convey an unanimous message that future societies will become dependent on unprecedented levels of human intervention, which raised questions among scholars about (1) the assumptions on the availability of these technologies and (2) the level of political (un)willingness accounted for in these modelled processes (Anderson and Peters, 2016; Geden, 2015; Peters, 2016). As IAMs do not account in much depth for various institutional, political, social, entrepreneurial and cultural factors, the ex-ante assessments could be considered as offering narrow technology-oriented perspectives on transitions towards a low-carbon society. In response to this caveat, various scholars have called for broader interdisciplinary research aimed at introducing greater realism into IAM scenarios (e.g. Kruger et al., 2016; Peters, 2016; Stern, 2016; Victor, 2015).

Earlier work has attempted to move beyond the techno-economic focus in integrated assessment modelling by implementing more realism into the integrated assessment frameworks. To incorporate greater realism, various methodological approaches have been developed and applied over time, such as, for example:

- Using qualitative storylines to outline the considered socio-political development over time in more detail (e.g. as found in the Special Report on Emission Scenarios (SRES) or Shared Socioeconomic Pathways (SSP) (Nakicenovic et al., 2000; O'Neill et al., 2014). Storylines are implemented via the use of broader rule-sets in IAMs, which allow to emulate real-world processes to a greater extent (such as the inclusion of limitations in joint international commitments and restricted availability of energy technologies, see e.g. Clarke et al., 2009; Kriegler et al., 2013; Kriegler et al., 2014);

- Devising participatory processes with stakeholders to incorporate qualitative elements in model-based scenarios on future change (Salter et al., 2010; van Asselt et al., 2003). Several methods are distinguished in literature to include a broader spectrum of value in IAMs, such as participatory modelling, facilitated modelling and interface-driven modelling (Salter et al., 2010), which describe the various modes in which participatory groups can contribute. Schmid and Knopf (2012) have, for example, applied a participatory modelling approach in which stakeholders are involved in model-based analyses via an iterative process of dialogues. Alternatively, the United Kingdom has engaged public stakeholders via the 'My2050' serious game interface, ${ }^{1}$ which allowed broader (social) learning about future transition routes (Comber and Sheikh, 2011);

- Making social systems more explicit or internally dynamic in IAM modelling. As IAMs are rooted in neo-classical economics, most assessment studies deploy a single rational agent which makes decisions based on cost-effectiveness considerations (De Cian et al., this issue). This singular view on decision making is acknowledged to not reflect the multi-dimensionality and complexity in social systems (Geels et al., 2017; Rotmans, 2006). To account for social systems in IAMs, model developments have focussed on expanding the single actor representation to a wider range of "consumer groups", which has gained some substance within transport modelling (see e.g. McCollum et al., 2016). Alternatively, the impacts of diverging social actor behaviours on a low-carbon transition have also been studied via stochastic modelling approaches that emulate numerous single actors and their preferences (Li, 2017).

Although these methodological approaches allow greater realism into the models' architecture, they all contain limitations. For example,

\footnotetext{
${ }^{1}$ http://my2050.decc.gov.uk/.
}

detailed qualitative storylines are still considered to be oversimplifications of reality, devising stylised representations of political, institutional and social change. Qualitative storylines can therefore only offer limited analytical support for planning future energy transitions. Moreover, although a broader representation of actors (real or virtual) allows for the adoption of more diverse strategies in integrated assessment modelling, the responses remain motivated by the technoeconomic principles included in the model. IAM scenario analysis may thus (1) expose a dominant focus on materialised change without taking note of the instigators and incubators driving the change and therefore (2) reason on current power relations and user practices in society without allowing other forms of governance and development.

Given the importance of social systems in accelerating or delaying transition processes, it is of interest to better reflect and study their influence on low-carbon transition strategies over time. In this study we therefore attempt to combine computer-based interpretations of systems change with insights of socio-technical transition studies. The study is framed around the European Unions' long-term objective of lowering total domestic greenhouse gas (GHG) emissions by $80 \%$ in 2050 compared 1990 levels. In the next section we first elaborate on the two analytical approaches used to combine techno-economic and sociotechnical assessment in a single study. Section 2 elaborates on the identification and operationalisation of shared concepts. Section 3 presents the scenario results in terms of energy supply and demand. Section 4 discusses the applied methods and Section 5 summarises and concludes.

\section{Towards an interdisciplinary analytical framework and its operationalisation}

\subsection{Selection of analytical approaches}

In this study, we combine two analytical approaches that offer different but complementary views on the evolution of low-carbon transitions.

The first analytical approach considers the evolution of low-carbon transitions through the techno-economic lens used in computer-based modelling. A wide variety of computer-based interpretations on lowcarbon transitions exist to date, which have been developed by (1) economic models, (2) energy system models or (3) integrated assessment models. Here, we predominantly focus on the TIMER model (van Vuuren, 2007), an energy system simulation model representing simplified economy-environment causal chains, which is nested in a broader framework on global systems change (IMAGE) (Stehfest et al., 2014). Combined, the TIMER/IMAGE model is able to reflect year-toyear investment decisions and the implications to the human and natural system based on specific rules about investment behaviour, fuel consumption, technological learning and diffusion patterns (van Vuuren, 2007). As recent model developments have led to more explicit representations of sectors and actors (see e.g. Daioglou et al., 2014; de Boer and van Vuuren, 2017; Girod et al., 2012; Isaac and Van Vuuren, 2009), the TIMER/IMAGE model provides opportunity to explicitly address social actor behaviour within the broader scope of global system change modelling.

The second analytical approach considers the evolution of lowcarbon transitions through diverse socio-technical developments. A variety of theoretic frameworks has emerged in the last few decades that provide insights into social actor behaviour in, and the governance of, low-carbon transitions (see for an overview e.g. Markard et al., 2012). The Multi-Level Perspective (MLP), as one of these theoretic frameworks, is a widely used analytical framework to study transitions (Geels, 2002; Geels and Schot, 2007). The MLP recognises that transitions are non-linear processes resulting from multiple endogenous and exogenous developments at three different analytical levels: the niche, regime and landscape level. We have specifically selected the MLP as it is a fairly established perspective within transitions studies and has (1) 
explicit consideration of the time dimension (linking future goals to near-term decisions), (2) relative narrative simplicity (e.g. struggle between niches and regimes in the context of slow-moving landscapes), (3) specification of systemic processes and underlying mechanisms, (4) explicit linkage of actors and material systems, and (5) is partly supported by similar historical insights as the model-based assessments.

Although the analytical approaches are acknowledged to be fundamentally different, several elements can be recognised that are in close proximity to each other which provides a promising starting point for further interaction. Given the differences in (1) assessment style (e.g. narrative-based vs. quantitative assessment), (2) analytical focus (e.g. emergent and disorderly developments vs. stylised trends that are extended into the future) as well as (3) the type of metric used to describe transitions (qualitative vs. quantitative descriptions of change), no full integration of both analytical approaches is pursued (Geels et al., 2016). We nonetheless agree with Turnheim et al. (2015) that "there are good grounds for a common framing of analytical and governance problems [to] be addressed by combining different lenses and styles of explanation" and describe a method for a softer integration of both transition conceptualisations in the following sections.

\subsection{Defining shared concepts}

A softer integration of IAM and MLP requires the identification of common concepts. In the formulation of both disciplinary philosophies we can detect several concepts that are considered key for both analytical approaches. These shared concepts provide some leeway for conceptual interaction. The following sections elaborate on these shared concepts.

\subsubsection{Niche momentum and system inertia}

A shared concept is recognised in the way how systemic change is interpreted in both analytical approaches. Although differences exist in the semantics and connotations, we find that both analytical approaches apply the concepts of niche momentum (departure from the status-quo) and system inertia (stability and robustness of a regime to maintain itself) to explain systemic change. For example:

- MLP applies the concepts of momentum and inertia to describe the success or failure of interactions between actors and social groups, which help to explain how systemic change has materialised and what the ramifications are to the existing regime. The analytical emphasis of MLP is on qualitative elements, such as power struggles, emergence of networks and coalitions, and the co-evolution of change processes across multiple dimensions (e.g. social, technical, economic, political or cultural dimensions).

- IAMs apply the concepts of momentum and system inertia to illustrate the projected rate of change over time for various quantitative indicators. As IAMs lean on more abstract generalised patterns of change, e.g. using learning and logistic growth curves to endogenously represent the evolution of technological growth and diffusion, they offer a more narrow outcome-based perspective on systemic change.

\subsubsection{Transition narratives}

Another shared concept is recognised in the effort to classify the course of systemic change in a so-called "transition narrative". Both analytical approaches devise (transition) narratives as a pragmatic research instrument to describe change, though each with a different purpose:

- The MLP perspective provides narrative explanations by focusing on the interactions between niches, regimes and landscapes. Given the rather intangible and fluid nature of many of the concepts addressed in MLP, the narrative approach offers the opportunity to codify and detect "generic" patterns that result from interactions between actors (e.g. groups making moves, taking actions and react to each other) (Geels and Schot, 2007).

- For IAMs, the narrative or storyline approach is generally used to create a context around the applied mathematics, computer syntax and parameterisation. Given how social systems find no direct analogue in IAMs, as they are implicitly encapsulated in the emulated system processes and mathematical formulations (see also De Cian et al., this issue), scenario narratives provide the opportunity to impose alternative sets of assumptions to the models' default configuration.

\subsubsection{From shared concepts to conceptual interaction}

In recognising and defining the shared concepts, it becomes clear that MLP embodies a wealth of information on the driving forces of socio-technical transitions, which is then collected in a transition narrative to create a vast corpus of explanation on systemic change. Alternatively, IAMs contain a wealth of information on causal (technoeconomic) interrelationships, which require corrective input to provide a (new) sequence of change over time. Conceptual interaction may therefore take the form of MLP informing IAMs on recent and emerging developments for a wide range of niche-innovations.

To remain compatible with, and comprehensible to, both analytical approaches, ${ }^{2}$ we identify two archetypical transition narratives that can function as an analytical bridge between both scientific approaches (drawn from Geels and Schot, 2007):

1. The first narrative (Technological Substitution) describes how stabilised niche-innovations are awaiting a window of opportunity to gain bigger market shares. This window of opportunity is described as a "specific shock" that initiates socio-technical change. The narrative represents a portfolio shift by regime actors, who are focussed on replacing existing socio-technical elements with versions that better fit with the new environment. Other elements (e.g. user practices, lifestyles, governance arrangements) remain close to the existing regime.

2. The second narrative (Broader Regime Change) describes a lack of faith in existing regimes to respond appropriately to the new environment. It includes a shift to a new socio-technical system, based on the breakthrough of radical niche-innovations that entail not only technical changes but also wider behavioural and cultural changes and new user practices and institutions.

Both analytical approaches benefit from identifying niche-innovations as part of either one of these narratives. For MLP it allows to provide a frame to which real-world developments can be structured (via recurrent patterns and deviations), whereas IAMs can devise these transition narratives to distinguish between two different types of actors that drive systems change (namely (1) incumbent actors that are seeking a new balance within an existing regime, or (2) new actors that are destabilising the existing regime and replacing it with something new).

Together the analytical approaches are found to share conceptual space in (1) the run-up towards the present situation (with MLP "input" oriented and IAM "outcome" oriented) and (2) the interpretation of how systems will evolve over time (with MLP encompassing knowledge of the build-up and tendency of niche-innovations to challenge the existing regime, while IAMs depict the course of development for niche-

\footnotetext{
${ }^{2}$ Recognising here that conceptual interaction needs (1) a level of simplicity (stylised but representative), (2) take note of both bottom-up developments as well as top-down (landscape or system-wide) pressures over longer periods of time (which allow a departure from the existing system) and (3) to pay specific attention to agents of change (given the lack of representation of social actor groups in IAMs).
} 


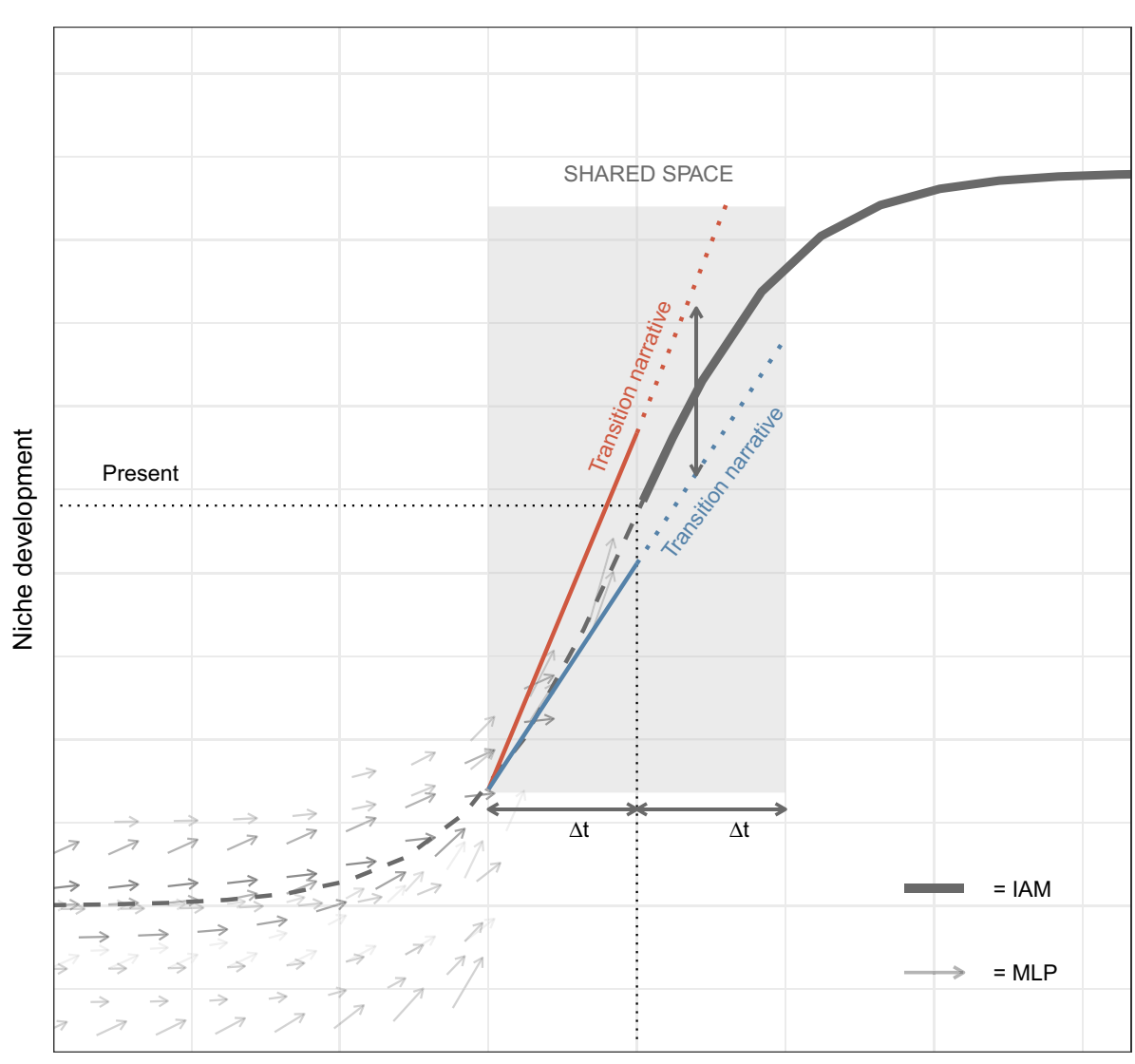

Time
Fig. 1. Illustration of the two considered analytical approaches and their shared conceptual space. The arrows represent the various niche developments that can be studied with MLP. The lines represent the stylised conceptualisation of system change based on historical "outcome" data (dashed) and the interpretation of the IAM on how it extends into the future (solid). $\Delta$ t represents the considered timespan for study in MLP, of which is assumed that the current orientation of niches can be projected into the future. The red and blue lines represent the outcome of conceptual interaction, in which MLP can provide insight on (1) niche momentum (as represented in the slope of the line) and (2) the strategic actor driving a niche-innovation (as represented in the colour of the line). This information allows IAM analysis to adopt more forward-looking perspectives into projections, while accounting for specific actor bases. (For interpretation of the references to color in this figure legend, the reader is referred to the web version of this article.) innovations under a changing landscape over time (see Fig. 1 for an illustrative example).

\subsection{Operationalising the interaction}

\subsubsection{Drawing insights from shared concepts}

Conceptual interaction between the two analytical approaches can be operationalised by drawing insights from case-studies looking into social and technological niche-innovations and using the information in quantitative modelling. In a first step, we have accumulated the findings of multiple case-studies to create a typology on systemic change. The case-studies have been selectively drawn from (1) exemplar countries in Europe (Germany, the Netherlands, United Kingdom and Sweden) and (2) three important economic domains (power, mobility, and heating). On average about 6-7 green niche-innovations have been selected per domain in each country for further study (see Supplementary information Table A1 for an overview).

The niche-innovations have been analysed across three analytical dimensions, which look into the (1) innovation and market trajectories (techno-economic assessment), (2) actors and social networks (sociocognitive assessment), and (3) the governance and policies over the last 10-15 years. The assessment as a whole allowed to draw an overall qualitative judgement of the current momentum of each niche-innovation, which is assumed to provide some indication of the potential towards the near future. Niche momentum could be judged as having "very low" (inert system) or "very high" (breakthrough) momentum with three intermediate values in between. In a similar fashion, the MLP assessment also provided insights into the subset of actors driving the change for niche-innovations by categorising the case-studies into either of the two transition narratives (respectively Technology substitution or Broader Regime Change).

The outcomes of the MLP assessments are visualised in Fig. 2. The typology reveals that the various countries and domains are at varying stages of an energy transition. The electricity systems throughout Europe expose niche developments with medium to high momentum, signalling that a transition is eminent for these niche-innovations. Niches in the mobility domain are mostly ranked as having medium to low momentum, signalling that a departure from the established system is in a much earlier phase. Niches in the heating domain, however, depict low to very low momentum, suggesting an inert system that is not likely to adopt any new practices soon. In general, the figure shows that technological innovations are currently advancing more than most social innovations, for which momentum is low. Interestingly, the niche-innovations appear to not uniformly classify into a certain transition narrative, implying that different motivations are driving nicheinnovation developments in different countries (for example, the development of onshore wind power has been mostly driven by incumbent actors in the UK, whereas the same niche was mostly adopted by new actors in Germany).

We apply equal weighing ${ }^{3}$ of the case-study findings to derive an overall momentum of change and deduct which actors are most likely involved in driving the change (represented by the bars in Fig. 2). This reveals to what extent niche-innovations (1) are likely to gain momentum and (2) are developed by a specific set of actors driving the change. Ambiguous outcomes underline an important caveat in our approach, as currently we only draw information on emergent

\footnotetext{
${ }^{3}$ One may argue whether equal weighing of the driving forces is an appropriate measure to trace out the course of change for a region as a whole. However, given how each represented EU Member State is (1) exemplar in the field of technological innovation, (2) bound to the same European GHG emission reduction target of $80 \%$ in 2050 compared to 1990 levels and (3) together represent a large share of emissions within Europe (representing $\sim 40 \%$ of total European GHG emissions over the last 20 years), the collective action among these regions can be considered characteristic of the overall lowcarbon transition strategy within the European context.
} 


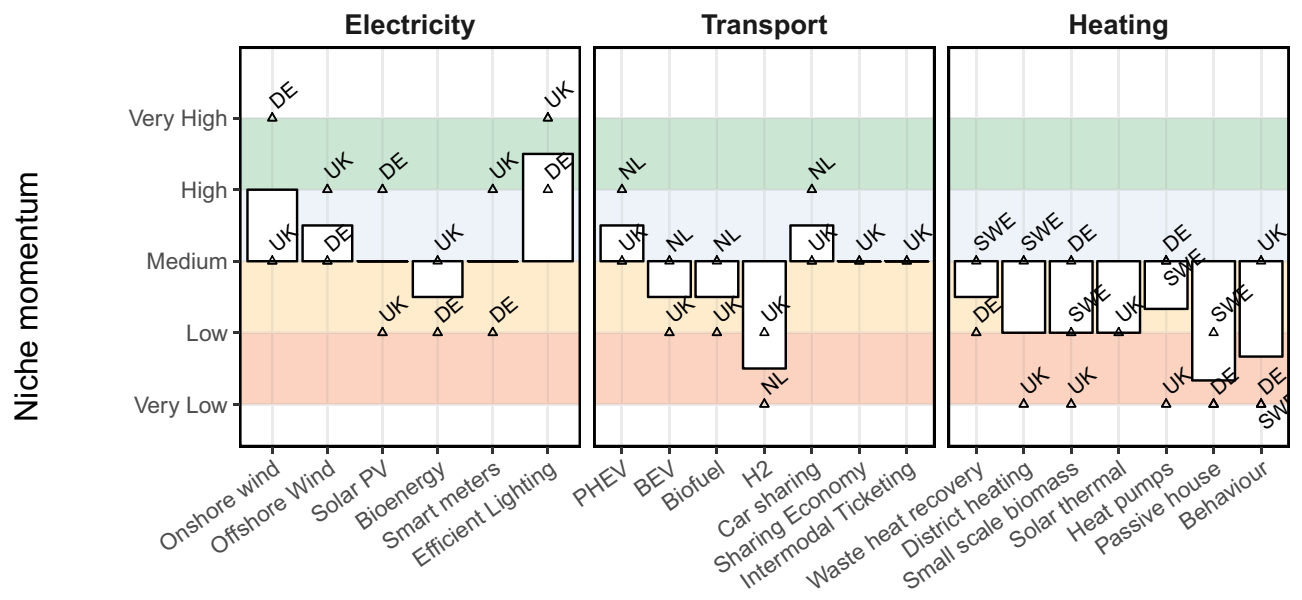

Fig. 2. Overview of niche momentum and actor per country (triangle) and the overall deducted patterns (bars). Electricity: DE (Rogge et al., 2015) UK (Geels et al., 2015). Mobility: NL (Turnheim et al., 2014) UK (Hodson et al., 2014). Heating: DE (Thema et al., 2014) UK (Turnheim and Berkhout, 2014) SWE (Nykvist and Dzebo, 2015). Abbreviations BEV: Battery Electric Vehicle. PHEV: Plug-in Hybrid Electric Vehicle. H2: Hydrogen fuelled vehicle.

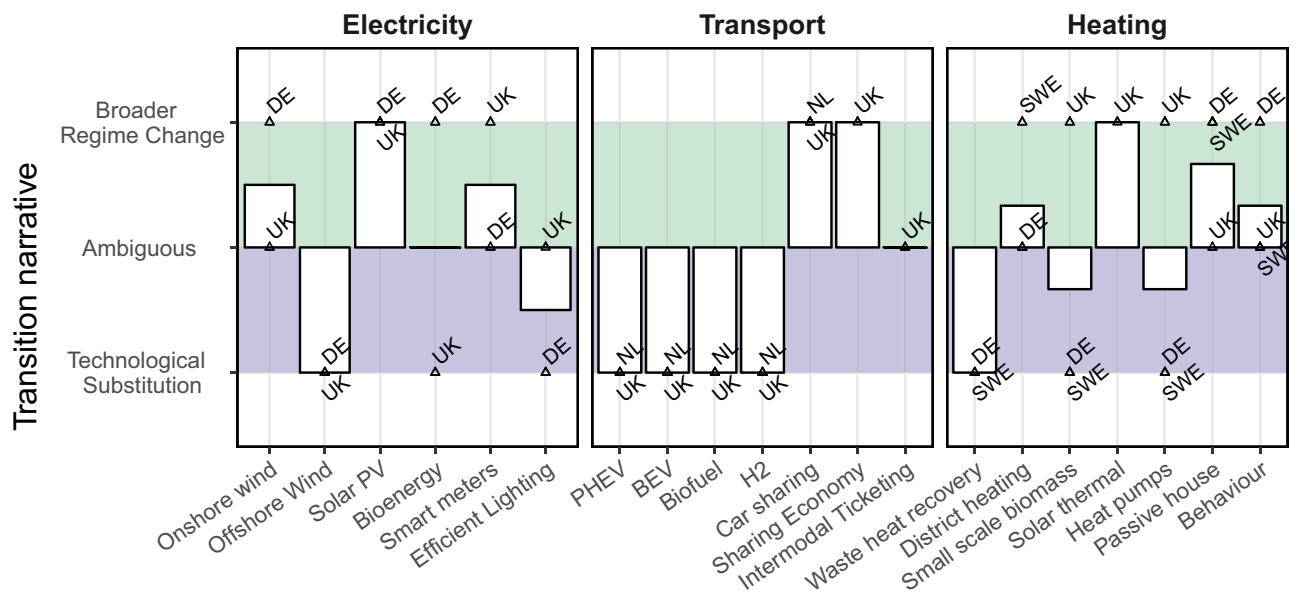

processes of change with a very prominent classification. Although we acknowledge that multiple interpretations are possible for the type of actor taking the lead, we leave a more pluralistic approach to future work. In the following section we elaborate on how these detectable patterns from MLP analysis have been used to develop IAM scenarios.

\subsubsection{Translating MLP insights into IAM analysis}

To study the effect of actors and actor behaviour on low-carbon transition strategies, we devise the TIMER/IMAGE integrated assessment model to test the course of development over the 2010-2050 time horizon. This requires a translation of the rich qualitative information as provided in the MLP studies to applicable input for the TIMER/ IMAGE model.

- To distinguish between specific actors driving change, we have used the typology of Fig. 2 as a guide to promote or weaken the representation of a niche-innovation in the respective scenario. We reason that a unanimous allocation of a niche-innovation to either one of the transition narratives provides confidence that a transition is driven by a specific strategic group of actors.

- Regarding the representation of "niche momentum" in the model, we have used the typology to provide a forward-looking perspective on the development and orientation of the represented niche-innovations (see Table A1 in the Supplementary information). High momentum would reflect a change with more immediate effect in the model, whereas lack of momentum, such as considered for most behavioural change niche-innovations (see Fig. 2), would result in a delayed effect.

In terms of actual implementation, translation is considered the process of locating the right context variables in the model and setting new values to the default parameterisation (leading to a new model response, as represented in the slope of the lines in Fig. 1). These context variables are specific to the model, leaving much of the translation to the interpretation of the modeller. Quantitative findings, such as assumptions about efficiency, can be adopted rather straightforward in a quantitative model. However, if the provided information does not allow to be translated into the mathematical formulations as used in the model (such as the accumulation of knowledge and the reordering of social rules), more stylised methods are employed to impose a change.

Stylised methods that can be implemented are the linking or locking of dynamical processes in the model. An example of this is the removal of the relative cost differences for specific technologies in a portfolio (e.g. by allowing the higher levelised costs of electricity for offshore wind to converge to the lower levelised costs of electricity for onshore wind over time). This narrative-based assumption would imply an accumulation of interest, leading to faster runs through the innovation cycles than under default assumptions in the model. Alternatively, an example of locking, or changing societal rule-sets, can be considered by not allowing any further growth compared to a certain base year or base value (e.g. no further growth of the household size beyond $40 \mathrm{~m}^{2}$ / cap in urban areas, as a "behavioural change" measure for the heating domain). Abstracting such interventions allows us to adopt a new parameterisation of the models' context variables without underpinning the change with explicit numerical evidence (see also van Sluisveld et al., 2016 for further examples). A full breakdown of specific assumption-based changes to the parameterisation of the TIMER/IMAGE model is presented in table B1 of the Supplementary materials.

The narratives have been implemented in an iterative process with the scientists involved with the MLP case-studies, leading to an 
interactive setting in which a "zero-order" implementation has been discussed and revised (see Turnheim et al., 2015 for a conceptual outline of the process). Some inconsistency may occur with the new parameterisation and the qualitative findings, as qualitative knowledge may not translate completely into a deductible quantitative input. Two deliberate inconsistencies have been adopted in the Broader Regime Change transition narrative - including no new construction of nuclear energy from the start of the simulation and no implementation of carbon capture and storage technologies - as these technologies had not been formally classified as niche-innovations.

\subsection{Defining transition narratives to a low-carbon Europe}

The typology as presented in Fig. 2 presents the orientation of nicheinnovations under current day considerations and provides only limited information on the implications over time under a changing landscape. Hence, to assess the effect of specific social system configurations on the low-carbon strategy, we impose an exogenous pressure that allows the transition scenarios to align with the European objective of reducing domestic GHG emissions by $80 \%$ in 2050 compared to 1990 levels. In IAMs this is usually done by introducing pricing policies that shift the balance in the models' decision mechanisms for technology and services deployment. In this study, we impose a continuous and increasing system pressure in the form of a carbon price. ${ }^{4}$ This carbon price should be seen as a generic policy pressure that leads to systemic behaviour oriented towards a low-carbon transition in line with the EU 2050 objective. The carbon price is harmonised across the two different transition narratives. Table 1 provides an overview of the scenario architecture in this study.

\section{Findings on new transition pathways}

To assess the effect of specific social system configurations on the low-carbon strategy we compare the numerical output (also called "pathways" if we consider the development over time) of the TIMER/ IMAGE model for both transition narratives to a regular rational-economic agent pathway. We particularly look at the emission pathways to gain insights into the overall human-climate interaction over time, and the technology deployment pathways to gain insights into the changes on the sector and technology level (Rosenbloom, 2017).

\subsection{Emission pathways}

The European emission reduction objective demands a clear deviation from current emission levels (see Fig. 3). Although all three scenarios meet the EU 2050 objective, they differ in terms of depth and timing of emission reductions. The new transition scenarios both show a faster reduction in GHG emissions than the Default pathway, with the RegChange scenario showing the fastest reductions. By 2050, the Default and TechSub scenarios both deploy negative emissions as a prominent strategy for the power sector. The TechSub scenario, however, shows to have a lower dependency on negative emissions due to taking note of specific socio-technical tendencies in technological growth and deployment. In the absence of negative emission technologies (RegChange), deeper emission reductions throughout all sectors are needed to remain aligned to the $80 \%$ emission reduction target in 2050. Fig. 3 also reveals that the main challenge for sectors is on mitigating $\mathrm{CO}_{2}$ emissions, as non- $\mathrm{CO}_{2}$ emissions show to be negated more rapidly.

\footnotetext{
${ }^{4}$ The common pricing policy assumed in IAMs is the so-called "carbon price" (or tax) which adds a disadvantage to technologies and services that devise fractions of carbon content within their functional unit. Although often called "carbon tax", this parameter may be interpreted in the widest form of top-down steering, and may therefore just as well represent other policy instruments leading to a cost-optimal implementation of policies.
}

\subsection{Technology pathways}

In comparing the technology deployment pathways, it is essential to distinguish between the demand and supply of energy. We use the total energy consumption for specific technologies and services (in EJ/yr) as the functional unit to compare across the various services (demand) and technologies (supply). The focus on energy consumption also allows an inter-sectoral comparison of both (1) (fuel) substitution behaviour or demand reduction (as can be deducted in the absolute values) and (2) insights on niche momentum or system inertia (as can be deducted from the relative contribution to the total).

\subsubsection{Sector-level changes}

A first indication of shifted or maintained systems can be obtained from examining changes in service demand. In the TechSub and Default scenarios, efficiency gains lead to a lower total energy demand in 2030 than in 2010, with no major difference between these scenarios (see Fig. 4). The RegChange scenario depicts larger reductions in total energy demand, mainly due to 1) lower household energy consumption as a result of lower space heating demand, and 2) lower energy consumption in transport as a result of reduced passenger air and road travel. Over a longer time horizon, total energy demand decreases further with the largest reductions in the RegChange scenario. Interestingly, the TechSub and RegChange scenarios become less dependent on liquid energy carriers than the Default scenario. For the TechSub scenario this can be explained by the accelerated electrification of the transport sector, while in the RegChange scenario this reduction represents a decline in air travel and an increase in public transport (train). In the RegChange scenario gaseous fuels are reduced more strongly than in the other scenarios as a result of a lower demand for space heating.

\subsubsection{Technological configurations}

Until 2030, both the TechSub and RegChange scenarios show no substantial differences for the power sector compared to the Default scenario. This implies some systemic inertia, which can be attributed to the lifetime of existing capital and the postponement of new investment decisions beyond the 2025-2030 timeframe in the model. Inertia is found to play a smaller role in the transport sector due to the lower capital lifetimes of cars compared to the technologies in the power sector. This becomes particularly visible in the significant change in the composition of the passenger vehicle fleet in the TechSub scenario by 2030, both compared to 2010 and to the other scenarios. The RegChange scenario does not seem to follow the developments as expected under cost-optimal representations, as total energy demand is much lower due to changes in travel demand and differences in the mode split (presented in Fig. 4). For the heating domain, all scenarios depict a dominant and even increasing role for natural gas in space heating in the short term.

Towards 2050, the TIMER/IMAGE model shows a shift to renewable energy technologies, with a preference for onshore wind under Default scenario settings. The narrative-based changes seem to affect the merit order, showing an increased preference for offshore wind in the TechSub, while the RegChange scenario shows a preference for a broader spectum of renewable energy solutions (as reflected in the relative contributions for solar power and onshore wind). Irrespective of having adopted constraints or not, nuclear energy shows to be eventually phased-out in both transition narratives. In the Default and TechSub scenario, nuclear energy appears to be substituted by fossil and bioenergy-based thermal power supply with coupling to carbon capture and storage (CCS) systems. As this is a more constant power source, it could be devised as spinning reserve to balance shortages in supply from the more intermittent energy sources. The RegChange scenario, on the other hand, depends more on intermittent energy technologies, showing only a marginal contribution of other technologies (such as bioelectricity and hydro power).

The effects of the transition narratives are also visible for specific 
Table 1

Overview of the scenario architecture.

\begin{tabular}{|c|c|c|c|c|}
\hline Transition narrative & Actor representation & Short name & Origin & Mitigation goal \\
\hline Historical reference & - & 2010 & TIMER/IMAGE & - \\
\hline Techno-economic optimisation & Rational-economic agent & Default & $\operatorname{SSPs}^{\mathrm{a}}$ & Global $2{ }^{\circ} \mathrm{C}^{\mathrm{b}}$ \\
\hline Technological substitution & Incumbents & TechSub & PATHWAYS $^{\mathrm{c}}$ & $-80 \%$ EU 2050 \\
\hline Broader regime change & New actors & RegChange & PATHWAYS ${ }^{\mathrm{C}}$ & $-80 \%$ EU 2050 \\
\hline
\end{tabular}

${ }^{\text {a }}$ For the purpose of this study we build on the new scenario framework for climate change research, also called Shared Socioeconomic Pathways (SSPs) (O'Neill et al., 2014). We select

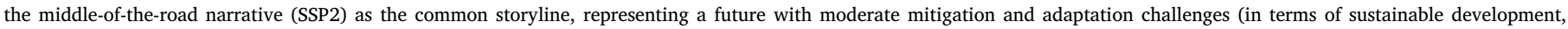
inequalities, technological change, and productivity of land).

$\mathrm{b}$ The mitigation goal here is defined as "Global $2^{\circ} \mathrm{C}$ " which represents a global commitment to limiting global warming by no more than $2{ }^{\circ} \mathrm{C}$ in 2100 with respect to the pre-industrial

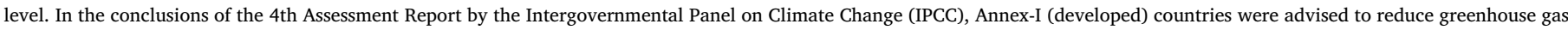

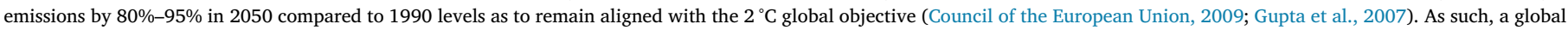
$2{ }^{\circ} \mathrm{C}$ objective can be considered compatible with meeting the EU objective in 2050 .

${ }^{\mathrm{c}}$ These scenarios have been developed as part of the PATHWAYS project, which explored transition pathways to a low-carbon, sustainable Europe under different disciplinary lenses (Geels et al., 2016; Turnheim et al., 2015).

Total greenhouse gas emissions (excl. LULUCF)
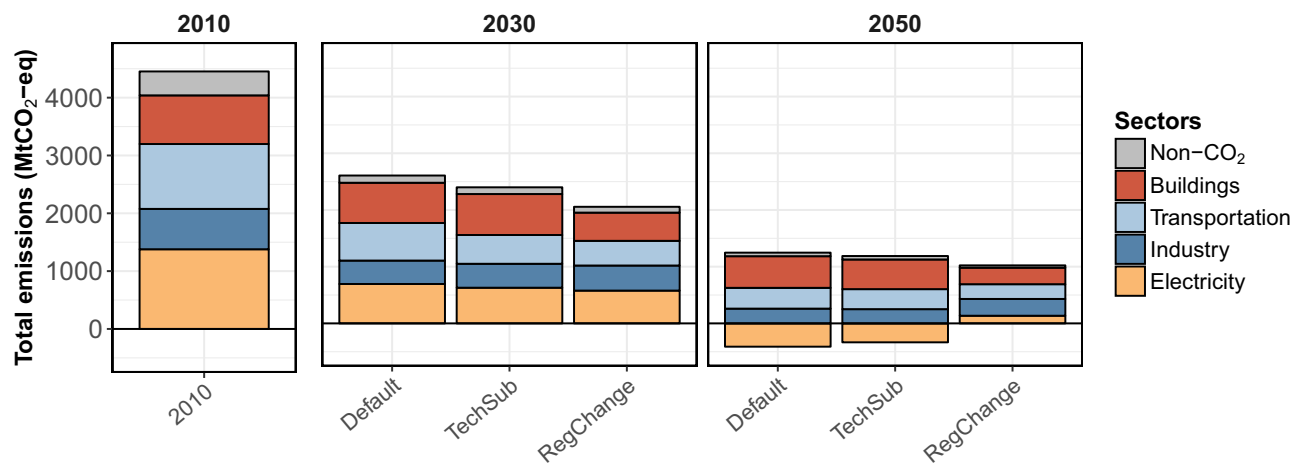

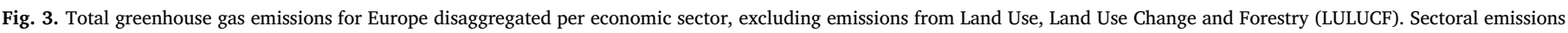
show total $\mathrm{CO}_{2}$ emissions per sector, the sum of non- $\mathrm{CO}_{2}$ emissions (representing $\mathrm{CH}_{4}, \mathrm{~N}_{2} \mathrm{O}$ and F-gasses) are depicted separately.

demands over time, such as found for private road travel and heating. We find that under the Default scenario the (gasoline-based) internal combustion engine (ICE) vehicle is maintained, with only some marginal diversification in the passenger car fleet by 2050. This is in stark contrast with the TechSub scenario, in which the battery electric vehicle (BEV) has almost fully overtaken the private vehicle fleet in road travel. The RegChange scenario is characterised by major reductions in total energy use for passenger travel as a result of behavioural change. Interestingly, although a scenario without "negative emission" technologies (RegChange) would necessitate the electrification of the energy demand sectors, some dependency remains on gasoline-based vehicles by 2050 . This model response can be explained by the higher dependency on renewable energy sources, leading to higher electricity prices and the perseverance of the existing regime. For heating, some rebound effects can be observed in the TechSub scenario, given the increase of oil-fired and gas-fired boilers compared to the Default scenario, indicating that electrification in some areas leads simultaneously to the strengthening of existing fossil-based regimes elsewhere. Only for the RegChange scenario some momentum is depicted for the considered niche-innovations, as "small scale biomass" and the "heat pump" (denoted as ASHP in Fig. 5) find some market share. The findings underline that the buildings domain is strongly inert; however, it should also be noted that the TIMER/IMAGE model has only a limited representation of the considered building stock and lacks explicit detail on the technology-level.

\section{Discussion}

In this study we have presented a method for conceptual interaction between integrated assessment modelling and insights from the multi- level perspective. The conceptual interaction started with formulating qualitative transition narratives. These narratives have been the main vehicle for carrying information on (1) the current momentum of various niche-innovations in three different sectors and (2) the strategic actors driving the change. In a follow-up step the qualitative narratives have been translated into quantitative scenarios that could be implemented into a computational integrated assessment model (TIMER/ IMAGE). The narratives thus provide a new logic to the driving forces of the model, with explicit focus on actors, for which modellers have selected appropriate numerical representations. However, as the embedment of social science insights into natural science oriented disciplines has taken the centre stage in this study (as raised in e.g. van Vuuren et al., 2012; Victor, 2015), a more pragmatic approach has been adopted to overcome specific methodological challenges. In the following sections these challenges are addressed in more detail, for which we distinguish between the narrative development phase and the qualitative-to-quantitative translation process.

\subsection{Narrative development}

A first methodological challenge relates to the interpretation of detailed information from MLP assessment.

To quantitatively assess the impact of a transition narrative with an IAM model like TIMER/IMAGE requires to (1) draw a uniform direction of change for each scenario and therefore (2) assume scalability and comparability of case-study results within the European resolution of the model. This is a deliberate narrowing of the richness and qualitative detail of the MLP assessments. In that regard, the established operational link is rather deterministic and static in nature, even though it is acknowledged that socio-technical elements are more volatile and 


\section{Sector-level changes}
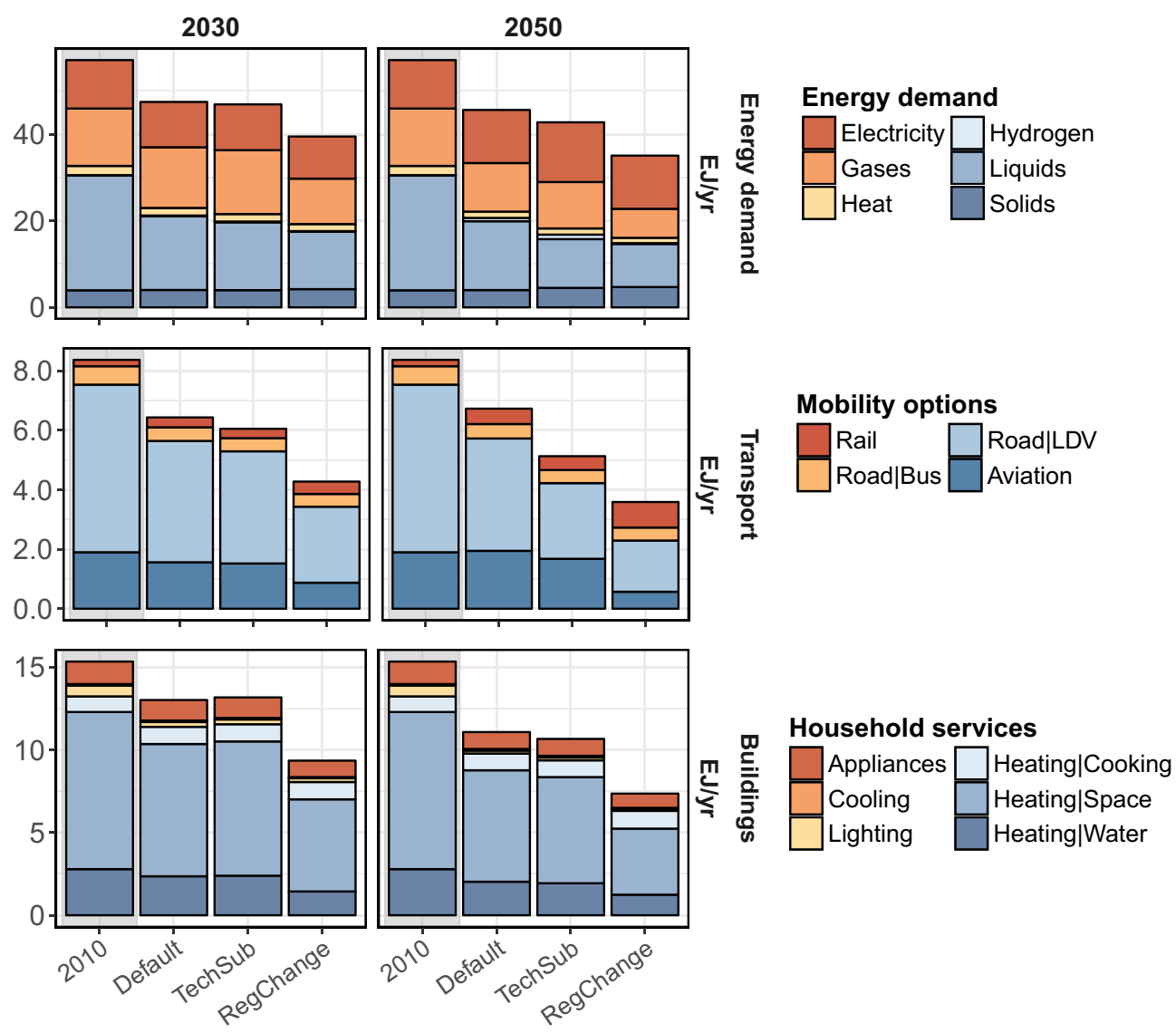

Fig. 4. Total final energy demand for each resource and total demand for transport and residential sector services in Europe.

changing over time. Scholarly literature has proposed various techniques and methods to develop and study a pluralist approach, or a wider range of narratives, addressing both the diversity and the vulnerability of transition narratives in a more structured and transparent way (see e.g. Guivarch et al., 2017; Trutnevyte et al., 2016; van 't Klooster and van Asselt, 2006; Wright et al., 2013). Future work could ideally focus on expanding the current methodology to concepts that account for changing settings. This would benefit the conceptual interaction between the analytical fields while leading to a better understanding of long-term transitions and the role of actors in driving the change.

A second methodological challenge relates to the prevailing technoeconomic focus in narrating low-carbon transitions. This techno-economic orientation may be a result of "availability" biases in both analytical approaches, which impose restrictions to how transitions and responses are explained in the current results. On the one hand, the selection of case-studies shows a preference for (1) technological substitution niche-innovations, (2) small-scale innovations over more large-scale system changes, and (3) existing concepts rather than new and disruptive innovations. Conversely, IAMs mostly connect to technologies and processes that are very thoroughly or explicitly modelled, particularly those with a proven experience base (such as large-scale, centralised, technologies). Hence, as broader regime changes are not explicitly nor quantitatively represented in the observational data or modelling, many questions relating to the (1) steering of socio-technical potential, (2) representations of new systems, and (3) negating the climatic response in the absence of "negative emission" technologies remain largely unresolved. How social niche-innovations could be represented in more detail would therefore need further methodological development.

\subsection{From qualitative-to-quantitative scenarios}

Specific literature exists on the translation of rich qualitative information of non-linear behaviour into applicable inputs for computational models (see Mallampalli et al., 2016 for an overview). However, despite the available knowledge base, the conversion and reproducibility of information remains the weakest link (Alcamo, 2008) for which no definitive solution exists. In this study we demonstrated a more pragmatic approach to bridging analytical differences by defining several operational links. Although it has created new avenues for interaction between two research communities, it is of importance to prolong the engagement with social sciences to build further experience in translating transition narratives to computational models (as is also recognised in Brown et al., 2015).

Furthermore, the current study restricts the analysis to only two transition narratives and one model interpretation. Adopting a more pluralistic approach in integrative assessment could broaden the knowledge on long-term development in line with the European climate objective. Particularly multi-model studies are commonly used to examine the effect of epistemic differences in understanding systemic change. However, given differences in the technological, spatial and actor-related resolutions across the range of applicable computational models, this creates difficulties in harmonising the translation process of qualitative transition narratives to comparable quantitative integrative assessment studies (see e.g. Hof et al., this issue, for a multimodel demonstration). Further methodological development on how to harmonise more detailed narrative-driven storylines across a wider range of models would reap benefits for long-term transition narrative assessments in the future. 


\section{Technological configurations}
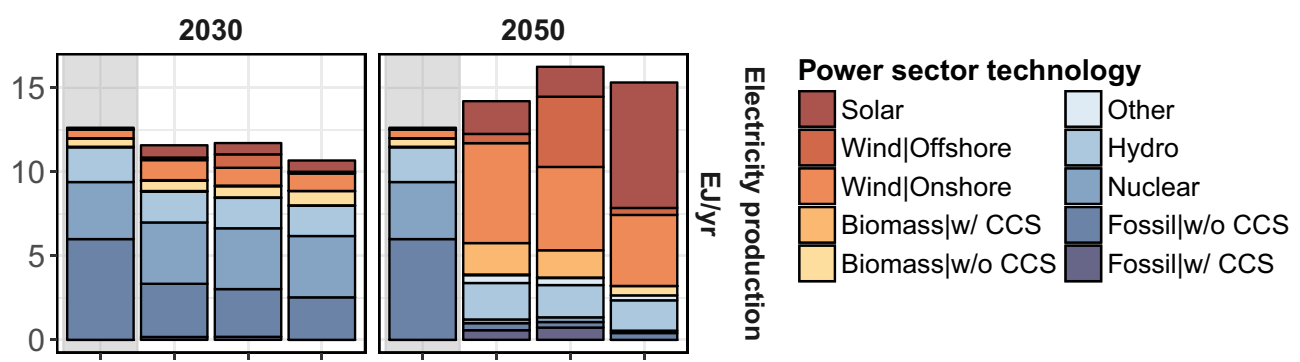

Fig. 5. Technology change for the power sector, passenger cars and heating technologies in Europe. CCS: carbon capture and storage. BEV: Battery Electric Vehicle. PHEV: Plug-in Hybrid Electric Vehicle. ICE: Internal Combustion Engine. ASHP: Air-source Heat Pump. Boiler|Mod.Bio: (advanced) biofuel-powered boilers/Bioler|Trad.Bio: Boiler powered on wood pellets.
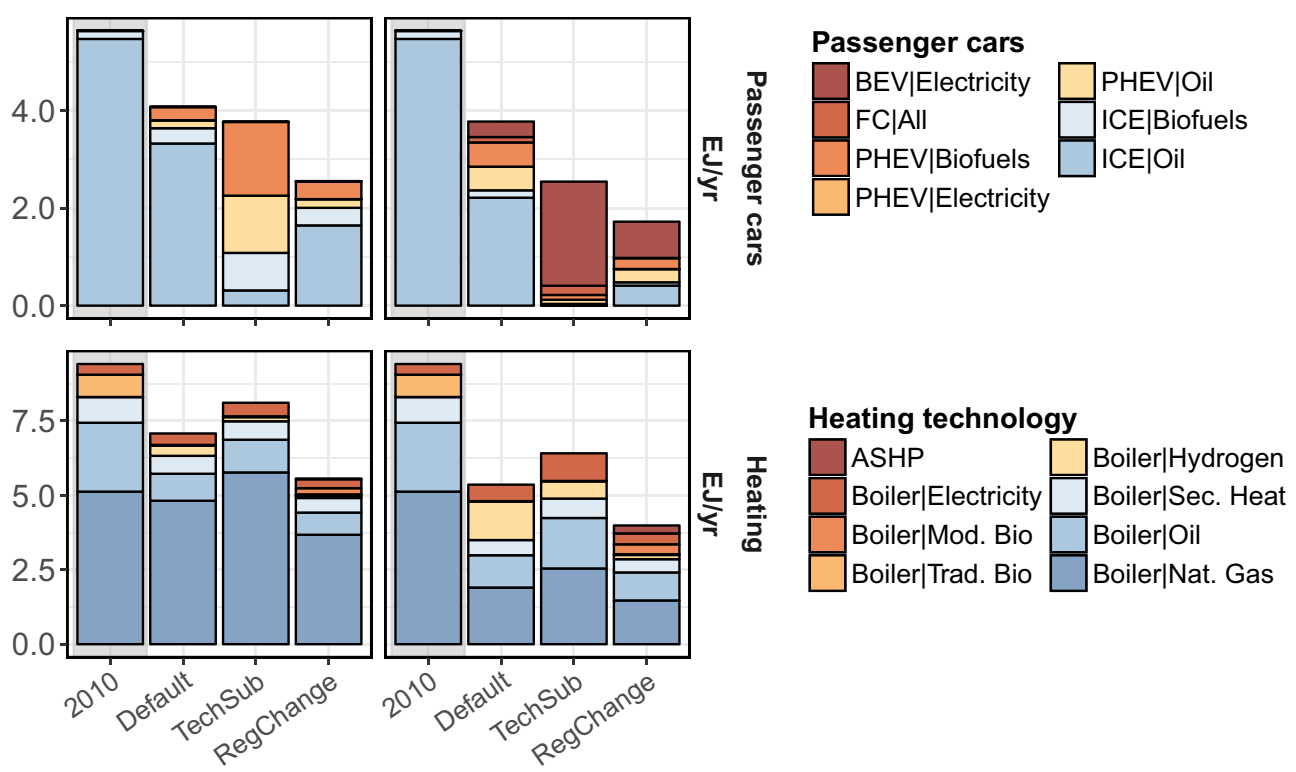

\section{Conclusions}

Integrated Assessment Models of global change (IAMs) contain a wealth of information on the interrelations and feedbacks between natural and human systems. However, simplified mathematical models on future global systems change leave room for debate on the representation of (1) actual system change and (2) the drivers of systems changes. Earlier work has focussed on improving (modelling) or framing (scenario narratives) the course of systemic change under carbon constraints, though remained evasive of explicitly addressing factors that shape change within society. This study has been motivated by the assumption that qualitative insights from socio-technical transition studies (MLP) can help inform model-based analysis (IAM) on the actors and processes driving change. By operationalising conceptual interaction between MLP and IAM, we have introduced a new analytical method to bridge the gap in qualitative and quantitative assessment of low-carbon transitions and propagated a new way to study and include more realistic emerging trends in futures studies. The study allows us to draw the following lessons:

\section{MLP can function as a useful heuristic for IAMs to analyse new and emerging directions of change}

By systematically and consistently assessing a variety of niche-innovations across a range of European countries with MLP, it provided a (1) snapshot of the current momentum in a wide range of niche-innovations and (2) a classification of the strategic actors mobilising a prospective transition (limited to incumbents and new actors). The results have powered two fundamentally different transition narrative scenarios with respect to the role of actors, the role of governance and the kind of technologies being considered. The impact of these differences could then be assessed with the TIMER/IMAGE model. The resulting transition narratives specifically allowed for a gradual and mixed implementation of impulses reflective of actual change in otherwise rather stylised representations of change in model-based scenarios. Although the conceptual interaction between MLP and IAM has strengthened the general understanding of systems change, several methodological challenges have been left unresolved. Future research could therefore focus on the further joining of methodologies to explore the effect of social actors in driving future low-carbon change.

Different pathways are compatible with meeting the $80 \%$ emission reduction target in Europe by 2050

The modelling exercise revealed that different transition pathways could meet the European GHG emission reduction objective for 2050. In the rationale of the considered transition narratives and as part of the mechanics of the TIMER/IMAGE model, this resulted into an explorative exercise on how a long-term objective could be met in the presence or absence of "negative emission" technologies. In the presence of such technologies, the transition scenario framed around technological substitution methods with a particular focus on decarbonising the power supply sector via carbon removal and storage technologies. In the absence of such technologies, intermittent renewable energy technologies and demand reductions were found to be notably more important in remaining aligned to the European GHG emission reduction objective. Despite an assumed low momentum for behavioural change niche-innovations in the present, the effect of demand-oriented solutions on reducing emissions is considered significant for those sectors and services that are in close proximity to the user (respectively heating and transport). In both transition scenarios, additional system pressure has been imposed to align current systems to 
the long-term climate objective. This underlines that public policies are important to drive either a more rapid technological transition (technology substitution) or to ensure that new actors can play a more important role (broader regime shift).

\section{Greater focus needed on demand-oriented solutions in techno-economic assessment}

Although the transition narratives have changed the responses of the TIMER/IMAGE model, most of the demand-oriented solutions find implementation via ad-hoc and assumption-based changes. As such, transition narratives that are dependent on more socio-cognitive changes or overall broader regime change may find only limited representation in techno-economic assessment. This leaves many questions relating to future (1) steering of socio-technical potential, (2) representations of new systems, and (3) negating the climatic response in the absence of "negative emission" technologies largely unanswered. These limitations should be devised as encouragement to pursue further development in this direction.

\section{Acknowledgement}

The research leading to these results has received funding from the European Union Seventh Framework Programme FP7/2007-2013 under grant agreement no 603942 (PATHWAYS) and the European Union's Horizon 2020 research and innovation programme under grant agreement no 730053 (REINVENT). SC acknowledges funding from the European Union's Horizon 2020 research and innovation programme under the Marie Sklodowska-Curie grant agreement no 706330 (MERCURY).

\section{Appendix A. Supplementary data}

Supplementary data to this article can be found online at https:// doi.org/10.1016/j.techfore.2017.10.024.

\section{References}

Alcamo, J., 2008. Chapter six the SAS approach: combining qualitative and quantitative knowledge in environmental scenarios. Dev. Integr. Environ. Assess. 2, 123-150.

Anderson, K., Peters, G., 2016. The trouble with negative emissions. Science 354, 182-183.

de Boer, H.S., van Vuuren, D.P., 2017. Representation of variable renewable energy sources in TIMER, an aggregated energy system simulation model. Energy Econ. 64, 600-611. http://dx.doi.org/10.1016/j.eneco.2016.12.006. ISSN 0140-9883.

Brown, R.R., Deletic, A., Wong, T.H.F., 2015. Interdisciplinarity: how to catalyse collaboration. Nature| 525 (7569), 315-317.

Clarke, L., Edmonds, J., Krey, V., Richels, R., Rose, S., Tavoni, M., 2009. International climate policy architectures: overview of the EMF 22 international scenarios. Energy Econ. 31 (Supplement 2), S64-S81.

Clarke, L., Jiang, K., Akimoto, K., Babiker, M., Blanford, G., Fisher-Vanden, K., Hourcade, J.-C., Krey, V., Kriegler, E., Löschel, A., McCollum, D., Paltsev, S., Rose, S., Shukla, P.R., Tavoni, M., van der Zwaan, B.C.C., van Vuuren, D.P., 2014. Assessing transformation pathways. In: Edenhofer, O., Pichs-Madruga, R., Sokona, Y., Farahani, E., Kadner, S., Seyboth, K., Adler, A., Baum, I., Brunner, S., Eickemeier, P., Kriemann, B., Savolainen, J., Schlömer, S., von Stechow, C., Zwickel, T., Minx, J.C. (Eds.), Climate Change 2014: Mitigation of Climate Change. Contribution of Working Group III to the Fifth Assessment Report of the Intergovernmental Panel on Climate Change. Cambridge University Press, Cambridge, United Kingdom and New York, NY, USA.

Comber, N., Sheikh, S., 2011. Evaluation and Learning From the 2050 Public Engagement Programme. Office for Public Management.

Council of the European Union, 2009. Brussels European Council 29/30 October 2009 presidency conclusions. https://www.consilium.europa.eu/uedocs/cms_data/docs/ pressdata/en/ec/110889.pdf.

Daioglou, V., Faaij, A.P.C., Saygin, D., Patel, M.K., Wicke, B., van Vuuren, D.P., 2014. Energy demand and emissions of the non-energy sector. Energy Environ. Sci. 7, 482-498.

De Cian, E., Dasgupta, S., Hof, A.F., van Sluisveld, M.A.E., Köhler, J., Pfluger, B., van Vuuren, D.P., 2018. Actors, Decision-making, and Institutions in Quantitative System Modelling, Technological Forecasting and Social Change, Part of the Special Issue on "Understanding Transition Pathways. Insights From Bridging Modelling and Transition-science Based Studies" (this issue).

Fuss, S., Canadell, J.G., Peters, G.P., Tavoni, M., Andrew, R.M., Ciais, P., Jackson, R.B., Jones, C.D., Kraxner, F., Nakicenovic, N., Le Quere, C., Raupach, M.R., Sharifi, A.,
Smith, P., Yamagata, Y., 2014. Betting on negative emissions. Nat. Clim. Chang. 4, $850-853$.

Geden, O., 2015. Policy: Climate Advisers Must Maintain Integrity.

Geels, F.W., 2002. Technological transitions as evolutionary reconfiguration processes: a multi-level perspective and a case-study. Res. Policy 31, 1257-1274.

Geels, F.W., Schot, J., 2007. Typology of sociotechnical transition pathways. Res. Policy 36, 399-417.

Geels, F.W., McMeekin, A., Hodson, M., 2015. Country Report 2: Green Niche-Innovations in the UK Electricity System.

Geels, F.W., Berkhout, F., van Vuuren, D.P., 2016. Bridging analytical approaches for lowcarbon transitions. Nat. Clim. Chang. 6, 576-583.

Geels, F.W., Sovacool, B.K., Schwanen, T., Sorrell, S., 2017. Sociotechnical transitions for deep decarbonization. Science 357, 1242.

Girod, B., van Vuuren, D.P., Deetman, S., 2012. Global travel within the 2 C climate target. Energy Policy 45, 152-166.

Guivarch, C., Lempert, R., Trutnevyte, E., 2017. Scenario techniques for energy and environmental research: an overview of recent developments to broaden the capacity to deal with complexity and uncertainty. Environ. Model. Softw. 97, 201-210.

Gupta, S., Tirpak, D.A., Burger, N., Gupta, J., Höhne, N., Boncheva, A.I., Kanoan, G.M., Kolstad, C., Kruger, J.A., Michaelowa, A., Murase, S., Pershing, J., Saijo, T., Sari, A., 2007. Policies, instruments and co-operative arrangements. In: Metz, B., Davidson, O.R., Bosch, P.R., Dave, R., Meyer, L.A. (Eds.), Climate Change 2007: Mitigation. Contribution of Working Group III to the Fourth Assessment Report of the Intergovernmental Panel on Climate Change. Cambridge University Press, Cambridge, United Kingdom and New York, NY, USA.

Hodson, M., Geels, F., McMeekin, A., 2014. Country Report 6: Green Niche-Innovations in the UK Mobility System.

Hof, A.F., Carrara, S., De Cian, E., Oehler, P., Pfluger, B., van Sluisveld, M.A.E., van Vuuren, D.P., 2018. From Global to National Scenarios: Bridging Different Models to Explore Power Generation Decarbonisation. Technological Forecasting and Social Change (in prep) Part of the Special Issue on "Understanding transition pathways Insights From Bridging Modelling and Transition-science Based Studies" (this issue).

Isaac, M., Van Vuuren, D.P., 2009. Modeling global residential sector energy demand for heating and air conditioning in the context of climate change. Energy Policy 37, 507-521.

Kriegler, E., Tavoni, M., Aboumahboub, T., Luderer, G., Calvin, K.V., Demaere, G., Krey, V., Riahi, K., Rösler, H., Schaeffer, M., van Vuuren, D.P., 2013. What does the $2{ }^{\circ} \mathrm{C}$ target imply for a global climate agreement in 2020? The LIMITS study on Durban platform scenarios. Clim. Change Econ. 04, 1340008.

Kriegler, E., Weyant, J.P., Blanford, G.J., Krey, V., Clarke, L., Edmonds, J., Fawcett, A., Luderer, G., Riahi, K., Richels, R., Rose, S.K., Tavoni, M., van Vuuren, D.P., 2014. The role of technology for achieving climate policy objectives: overview of the EMF 27 study on global technology and climate policy strategies. Clim. Chang. 123, 353-367.

Kruger, T., Geden, O., Rayner, S., 2016. Abandon hype in climate models. Guardian.

Li, F.G.N., 2017. Actors behaving badly: exploring the modelling of non-optimal behaviour in energy transitions. Energ. Strat. Rev. 15, 57-71.

Mallampalli, V.R., Mavrommati, G., Thompson, J., Duveneck, M., Meyer, S., LigmannZielinska, A., Druschke, C.G., Hychka, K., Kenney, M.A., Kok, K., Borsuk, M.E., 2016. Methods for translating narrative scenarios into quantitative assessments of land use change. Environ. Model. Softw. 82, 7-20.

Markard, J., Raven, R., Truffer, B., 2012. Sustainability transitions: an emerging field of research and its prospects. Res. Policy 41, 955-967.

McCollum, D.L., Wilson, C., Pettifor, H., Ramea, K., Krey, V., Riahi, K., Bertram, C., Lin, Z., Edelenbosch, O.Y., Fujisawa, S., 2016. Improving the behavioral realism of global integrated assessment models: An application to consumers' vehicle choices. Transp. Res. Part D: Transp. Environ. (1361-9209) 55, 322-342. http://dx.doi.org/10.1016/j. trd.2016.04.003.

Nakicenovic, N., Alcamo, J., Davis, G., de Vries, B., Fenhann, J., Gaffin, S., Gregory, K., Grübler, A., Jung, T.Y., Kram, T., Emilio la Rovere, E., Michaelis, L., Mori, S., Morita, T., Pepper, W., Pitcher, H., Price, L., Riahi, K., Roehrl, A., Rogner, H., Sankovski, A., Schlesinger, M., Shukla, P., Smith, S., Swart, R., van Rooyen, S., Victor, N., Dadi, Z., 2000. IPCC Special Reports: Special Report on Emissions Scenarios. Cambridge University Press, Cambridge, UK.

Nykvist, B., Dzebo, A., 2015. Country Report 3: Green Niche-Innovations in the Swedish Heat System.

O'Neill, B.C., Kriegler, E., Riahi, K., Ebi, K.L., Hallegatte, S., Carter, T.R., Mathur, R., van Vuuren, D.P., 2014. A new scenario framework for climate change research: the concept of shared socioeconomic pathways. Clim. Chang. 122, 387-400.

Peters, G.P., 2016. The 'best available science' to inform $1.5^{\circ} \mathrm{C}$ policy choices. Nat. Clim. Chang. 6, 646-649.

Rogge, K.S., Boedeker, P., Dallinger, D., Fleiter, T., Friedrichsen, N., Klobasa, M., Lehmann, J., Michaelis, J., Pudlik, M., Ragwitz, M., Wietschel, M., 2015. Country Report 1: Green Niche-Innovations in the German Electricity System.

Rosenbloom, D., 2017. Pathways: an emerging concept for the theory and governance of low-carbon transitions. Glob. Environ. Chang. 43, 37-50.

Rotmans, J., 2006. Tools for integrated sustainability assessment: a two-track approach. Integ. Assess. Int. J. 6, 35-57.

Salter, J., Robinson, J., Wiek, A., 2010. Participatory methods of integrated assessment-a review. Wiley Interdiscip. Rev. Clim. Chang. 1, 697-717.

Schmid, E., Knopf, B., 2012. Ambitious mitigation scenarios for Germany: a participatory approach. Energy Policy 51, 662-672.

Stehfest, E., van Vuuren, D.P., Kram, T., Bouwman, L., Alkemade, R., Bakkenes, M., Biemans, H., Bouwman, A., den Elzen, M., Janse, J., Lucas, P.L., van Minnen, J., Muller, M., Prins, A.G., 2014. Policy Applications Integrated Assessment of Global Environmental Change With IMAGE 3.0 - Model Description and Policy Applications.

Stern, N., 2016. Economics: current climate models are grossly misleading. Nature 
407-409.

Thema, J., Nanning, S., Buhl, J., Götz, T., Adisorn, T., Kurth, J., Manirjo, N., Echternacht, L., Berg, H., 2014. Country Report 4: Green Niche-Innovations in the German Heat System.

Trutnevyte, E., Guivarch, C., Lempert, R., Strachan, N., 2016. Reinvigorating the scenario technique to expand uncertainty consideration. Clim. Chang. 135, 373-379.

Turnheim, B., Berkhout, F., 2014. Country Report 5: Green Niche-Innovations in the UK Heat System.

Turnheim, B., Håkansson, I., Berkhout, F., 2014. Country Report 7: Green NicheInnovations in the Dutch Mobility System.

Turnheim, B., Berkhout, F., Geels, F., Hof, A., McMeekin, A., Nykvist, B., van Vuuren, D., 2015. Evaluating sustainability transitions pathways: bridging analytical approaches to address governance challenges. Glob. Environ. Chang. 35, 239-253.

van Asselt, M.B., Rotmans, J., Kasemir, B., Jäger, J., Jaeger, C., Gardner, M., 2003. From projects to program in integrated assessment research. In: Public Participation in Sustainability Science: A Handbook, pp. 215-227.

van 't Klooster, S.A., van Asselt, M.B.A., 2006. Practising the scenario-axes technique. Futures 38, 15-30.

van Sluisveld, M.A.E., Martínez, S.H., Daioglou, V., van Vuuren, D.P., 2016. Exploring the implications of lifestyle change in $2{ }^{\circ} \mathrm{C}$ mitigation scenarios using the IMAGE integrated assessment model. Technol. Forecast. Soc. Chang. 102, 309-319.

van Vuuren, D.P., 2007. Energy systems and climate policy - long-term scenarios for an uncertain future. In: Copernicus Institute of Sustainable Development. Utrecht University.

van Vuuren, D.P., Kok, M.T., Girod, B., Lucas, P.L., de Vries, B., 2012. Scenarios in global environmental assessments: key characteristics and lessons for future use. Glob. Environ. Chang. 22, 884-895.

Victor, D., 2015. Climate change: embed the social sciences in climate policy. Nature 520 (7545), 27-29.

Wright, G., Cairns, G., Bradfield, R., 2013. Scenario methodology: new developments in theory and practice. Technol. Forecast. Soc. Chang. 80, 561-565.

Mariësse A.E. van Sluisveld is researcher at PBL Netherlands Environmental Assessment Agency and Utrecht University, the Netherlands. She holds a $\mathrm{PhD}$ from Utrecht University. Her current work focuses on alternative transition pathways to meeting longterm climate policy targets.

Andries F. Hof is senior researcher at PBL Netherlands Environmental Assessment Agency and guest researcher at the Faculty of Geosciences, Utrecht University. He holds a university degree in economics (1999), after which he conducted research at several institutes in the Netherlands, Germany, and the US. In 2007, he started working on a EU research project about mitigation and adaptation strategies for climate change policy at $\mathrm{PBL}$ and received his $\mathrm{PhD}$ with this topic in 2010. Andries has authored more than 50 publications in peer-reviewed journals.
Detlef P. van Vuuren is professor of integrated assessment of global environmental change at Utrecht University, the Netherlands, and senior researcher at PBL Netherlands Environmental Assessment Agency. His work concentrates on scenario analysis of response strategies to global environmental change issues. Detlef van Vuuren has published over 240 peer-reviewed articles and has been an author on a large number of integrated assessment reports.

Bruno Turnheim is a Research Fellow at the Manchester Institute for Innovation Research (MIoIR) (University of Manchester), a Research Associate at King's College London, Associate Faculty at SPRU (University of Sussex), and an Associate Member of the Laboratoire Interdisciplinaire Sciences Innovations Sociétés (UMR-LISIS) (CNRSIFRIS). He holds a PhD from SPRU (University of Sussex). His research focuses on various aspects related to sustainability transitions, including questions of governance, the influence of normative problems, the destabilisation of existing regimes, the role of innovation and experimentation, and questions of interdisciplinarity.

Frank W. Geels is Professor of System Innovation and Sustainability at the Sustainable Consumption Institute (SCI) and the Manchester Institute of Innovation Research (MIoIR) at the University of Manchester. Geels is chairman of the international Sustainability Transitions Research Network (www.transitionsnetwork.org), and one of the worldleading scholars on socio-technical transitions and system innovation.

Samuel Carrara is researcher at Fondazione Eni Enrico Mattei (FEEM), Milan, Italy. His main research interests include renewable energies, sustainable development, energy policies, climate and energy economics, advanced energy systems and transportation. In early 2016 he was granted a Marie Skłodowska-Curie Global Fellowship by the European Commission, which is characterised by an outgoing phase as a visiting scholar at the University of California, Berkeley in 2017 and a return phase at FEEM in 2018.

Karoline Rogge is Senior Lecturer in Sustainability Innovation and Policy at the Science Policy Research Unit (SPRU) and Co-Director of the Sussex Energy Group at the University of Sussex, and Senior Researcher at the Fraunhofer Institute of Systems and Innovation Research (ISI). Her interdisciplinary research focuses on the link between policy mixes and low carbon innovation and energy transitions. Karoline holds a $\mathrm{PhD}$ from ETH Zurich.

Måns Nilsson is Research Director and Deputy Director at SEI and part time Professor of the Practice of Environmental Strategies and Policy Analysis at the Royal Institute of Technology (KTH). Key areas of interest are in low carbon energy and transport policies, development studies and the 2030 agenda, innovation and transitions, and institutions and governance. He received his MSc in International Economics from University of Lund, Sweden, and his PhD degree in Policy Analysis from Delft University of Technology, Netherlands. 